\title{
Potential Risk Characteristics of Adolescent Pregnancy in Schools and out of school in Kavango Region, Namibia
}

\author{
Article by Taimi Amakali-Nauiseb ${ }^{1}$, Honore K.Mitonga ${ }^{2}$ \\ ${ }^{1,2}$ University of Namibia University of Namibia \\ E-mail: ${ }^{1}$ tnauiseb@unam.na
}

\begin{abstract}
The objective is this study is to determine the potential risk characteristics among the in-school and out of school adolescents in Kavango region, Namibia.

A cross-sectional analytical study was conducted using mixed methods - quantitative and qualitative approaches among 350 school learners (grade 6 to grade 12) and 150 school drop-out adolescents (aged 12 to 19 years). The stratified random sampling techniques were used in the selections of the circuit and the schools. Structured questionnaires were used in face-to-face interviews, and in depth interviews were conducted among the key informants (teachers).

The following variables include the potential risk characteristics alcohol used, drug used, marijuana used, more than one sexual partner in past 12 months, partner older than 5 years, orphan, abortion, sex regularly, mothers education, contraceptive used, current pregnancy and outcome of birth.

Descriptive statistics was used to summarise the above mentioned variables. Cross-tabulations of demographic, sexual and economic variables were used to describe the relative frequencies.

The associations between different categorical variables were assessed using Chi-square test whilst the identification of different determining factors was analyzed with the epidemiological methods using odds ratios and/or estimated relative risks. The means, standard deviation and $95 \%$ confidence interval were computed. The differences between different variables or factors were considered to be statistically significant for p-values less than 0.05 .
\end{abstract}

Keywords: Adolescence, Adolescents Contraceptives, First intercourse, Sexual health, Sexual partner.

\section{Introduction}

The article covers the results related the potential risk characteristics among the in-school and out of school adolescents in Kavango region, Namibia.

This article was extracted from the authors study "a model for reproductive health and pregnancy preventing strategies among adolescents in schools in Kavango region, Namibia. With the commemoration of the World Population Day the United Nations Population Fund (UNFPA) released these statistics in, celebrated on the 11 July every year. This year the theme was "Investing in Teenage Girls "When the statistics were compiled, there were 245431 adolescent girls population in Namibia aged between 15 and 19. 46000 adolescent fell pregnant, 66\% of the population under the age, $39 \%$ below the age of 15 . The figures are higher in some regions, with $20 \%$ of teenagers in some rural areas becoming mothers earlier than their counterparts in urban areas. One of the reasons being is that rural teenage girls only have primary-level education, while girls in urban areas are better educated. Apart from the academic factor, the report also said some girls do not know how to avoid falling pregnant, while others feel shy or are ashamed to access contraceptives (Namibian newspaper, 14 July 2016), (UNFPA, 2013).

Adolescent pregnancy is an increasing problem in Namibia. Adolescent pregnancies are associated with a higher risk of complications during pregnancy and childbirth because the girls are physically and emotionally immature. Although many children become sexually active between 15 and 18 years, they do not have access to correct and relevant information on sexual matters. Pregnancy before the 
age of 18 years, and especially before the age of 16 years, carries a considerable risk to the health of the mother. Adolescent pregnancy increases the risk of ectopic pregnancy, pre-eclampsia, eclampsia, premature rupture of membranes, preterm labor, and cesarean among mothers up to 16 years of age (Omar et al., 2010).

Although different regions of Namibia are affected, Kavango region in Northern Namibia is mostly affected by the problem of teenage pregnancy. According to a USAID (2011) report, the region has the highest rate of 34\% teenage pregnancy among 15 to 19 year olds.

In Namibia, Mufune (2003) showed that taboos and social sanctions against prohibited social behavior have changed markedly; thereby loosening community control over sexuality and sexual behaviors that may predispose to HIV/AIDS related risk(Lillian \& Mumbango 2015).

\section{Objectives}

The objective is this study is to determine the potential risk characteristics among the in-school and out of school adolescents in Kavango region, Namibia.

Limitation of the study

The study focused only on public schools in Kavango region. Therefore, the outcomes of the study can only be recommended developing a model for adolescents within the public schools in Kavango regions. Consequently, the findings of the study need to be adjusted to the rest of the other schools in other regions in the country in order to be generalized. So, yes generalization of findings to the whole Namibian country will be applicable and will be done. Generalization of the study to Africa, the answer will be no because the model need to be adapted according to the countries culture and needs which need to be country specific. The model needs to be benchmark and due to constraints in time and resources implementation and evaluation of the model will not be completed now at the specific point in time.

\section{Delimitation of the study}

The study was carried out solely in Kavango region and not in any other regions of the country. The model needs to be benchmark and due to constraints in time and resources implementation and evaluation of the model will not be completed now at the specific point in time.

\section{Methods}

\section{Study design}

A cross-sectional analytical study was conducted using mixed methods - quantitative and qualitative approaches among 350 school learners (grade 6 to grade 12) and 150 school drop-out adolescents (aged 12 to 19 years). The stratified random sampling techniques were used in the selections of the circuit and the schools. Structured questionnaires were used in face-to-face interviews, and in depth interviews were conducted among the key informants (teachers). The following variables were included the potential risk characteristics alcohol used, drug used, marijuana used, more than one sexual partner in past 12 months, partner older than 5 years, orphan, abortion, sex regularly.

\section{Study population}

The study population groups were in three fold, the school learners in primary or secondary school, the teachers at different schools and the adolescent's in the community who had dropped out of school.

\section{Target population}

The first target population were the school learners falling within the age group of between 12- 19 years, in public primary and as well secondary schools in Kavango region. The second target population were teachers at different schools teaching Life Science, Life Skills, Biology or Natural 
Science. The third target populations were the adolescent's in the communities who had dropped out and or never went to school and falls within the age group of between 12- 19 years.

\section{Sample size}

A sample size of 500 adolescents was determined using Epiinfo version 7 considering at least 95\% significance level.

\section{Data collection: preparing the field}

For both the schools and the community: Prior telephonic arrangements were done with the school principals and councilors regarding the purposes of the visit, date and time for the visits to Kavango Region and to the specific schools.

Data collection procedure at schools

The researcher reported at the principal office whereby the researcher submitted all written proof of letters for permission as obtained from the different institutions. The principal accompanied the researcher to the Laboratory classroom or Life Skills class where the data collection took place. At some schools, the teacher responsible for Life Science, Life Skills, Natural Science or Biology accompanied the researcher to the Laboratory classroom or to the Life Skills class where the data collection took place. At some instances the learners waited at the mentioned classrooms and at other schools learners were called for the data collection once the researcher turned up.

The researcher was provided in-advance with the class-list of the specific grades, and carried out simple random selection. At the Primary schools: all learners from the different grades 6-7 came to the one central classroom, which was the Life Skills class's room. At the Secondary schools: all learners from the different grades 8-12 came to the one central classroom, which was the Life Skills, Biology or the laboratory classroom. After explaining the aims of the study and obtaining permission from the learners, the researcher distributed the questionnaires to each learner. The questionnaires were in English and consisted out of open ended close questions. The researcher utilized questionnaires with the learners to understand their take on the curriculum provided at schools. Questionnaires on the learners were used to collect data and an individual in-depth face-to-face interview was carried out with the teachers offering at school the abovementioned subjects. The teacher's in-depth interview pointed out their challenges, experiences and shortcomings with the implementation of the curriculum. The data collected by the main researcher focused on reproductive issues, whether it is included and discussed comprehensively or partly in the abovementioned subjects. The questionnaire's consisted out of five subsections which were as follows: demographic data; sexual and reproductive health characteristics, potential risk characteristics, family planning and social background.

\section{Data collection procedure in the community}

The constituencies were visited on different days. The researcher reported at the constituencies' office and the representative of the councilor was waiting as prior arranged.

\section{Conducting interviews}

After explaining the aims of the study and obtaining permission from the adolescents the researcher distributed the questionnaires to each learner. The researcher distributed the questionnaire to the learners and they responded to the questionnaires accordingly, the researcher was present for any possible questions or clarity. The learners took approximately 30-45 minutes to respond to the questionnaires.

\section{Data analysis}

Data were entered and analyzed using SPSS software version 23 was used in data analyses. Descriptive statistics was used to summarize the above mentioned variables. Cross-tabulations of demographic, sexual and economic variables were used to describe the relative frequencies. 
The associations between different categorical variables were assessed using Chi-square test whilst the identification of different determining factors was analyzed with the epidemiological methods using odds ratios and/or estimated relative risks. The means, standard deviation and $95 \%$ confidence interval were computed. The differences between different variables or factors were considered to be statistically significant for p-values less than 0.05 .

\section{Results}

In table $1,1.6 \%$ of adolescents who did perform abortion are orphaned; $1.0 \%$ of adolescents who did not perform abortion are not orphaned.2.6\% of adolescent perform abortion which indicated that this is a public health concern and is statistically significant with a p-value of 0.004 .

As illustrated in table 2, the orphans with $95 \%$ confidence interval odd ratios varying between 1.457 to 3.720; the researcher found that the orphans are 2.360times at risk of performing abortion and those who are not orphans are 0.520 times at risk of performing abortion, with $95 \%$ confidence interval odd ratios varying between 0.261 to 1.037 . This results show that the orphaned adolescent have a minimum risk of performing abortion 0.052 times and a maximum risk of performing abortion of 2.360 times.

As pointed out in table 2,0.2\% of adolescents who did perform abortion are smoking marijuana; 2.4 $\%$ of adolescents who did not perform abortion are not are smoking marijuana. $2.6 \%$ of adolescent perform abortion, which indicated that this is a public health concern.

The adolescents who smoke marijuana with $95 \%$ confidence interval odd ratios varying between 0.356 to 17.516; the researcher found that those who smoke marijuana 2.497 times at risk of performing abortion and those who do not who smoke marijuana are 0.952 times at risk of performing abortion, with $95 \%$ confidence interval odd ratios varying between 0.813 to 1.115 . The results show that the adolescent who smoke marijuana have a minimum risk of performing abortion 0.952 times and a maximum risk of performing abortion of 2.497 times (table 2).

$0.6 \%$ of adolescents who performed abortion are using drugs; $2.0 \%$ of adolescents who did not perform abortion are not are using drugs. 2.6\% of adolescent perform abortion, which indicated that this is a public health concern and is statistically significant with a p-value of 0.000 (table 2).

In table 2, the adolescents who used drugs with $95 \%$ confidence interval odd ratios varying between 3.499 to 36.092; the researcher found that those who used drugs are 11.238 times at risk of performing abortion and those who do not who are using drugs are 0.785 times at risk of performing abortion, with $95 \%$ confidence interval odd ratios varying between 0.583 to 1.058 . The results show that the adolescent who are used drugs have a minimum risk of performing abortion 0.785 times and a maximum risk of performing abortion of 11.238 times.

Table4, an association exist between gender of participants, had sex regularly, alcohol, and circumstances used are statistically highly significant ( $\mathrm{p}$-value $=0.001<0.05 ; \mathrm{p}-$ value $=0.002<0.05$; $\mathrm{p}$-value $=0.001<0.05 ; \mathrm{p}$-value $=0.031<0.05$ ).

Table 4, the association between gender of participants, mother's education, partner older than 5years and contraceptives is statistically significant $(\mathrm{p}-$ value $=0.042<0.05 ; \mathrm{p}-$ value $=0.031<0.05 ; \mathrm{p}$ -value $=0.030<0.05)$.

Table 5, a highly statistically significant exists between gender of participants, more than one sexual partner in past 12 months and outcome of birth is ( $\mathrm{p}$-value $=0.003<0.05$; $\mathrm{p}$-value $=$ $0.001<0.05)$.

\section{Discussion}

Adolescent pregnancy was considered a private matter that only involved the pregnant adolescent and the immediate family members. This issue has now however become a public concern. It is linked to concerns such as the spread of HIV/ AIDS, non-marital births, sexual abuse and neglect, abortions, infant and maternal mortality, high rate of unemployment, school failure and drop-outs, and loss of self-esteem and limited future career opportunities (Lillian \& Mumbango, 2015). 
The study by Liang, (2013) mentioned that the young adolescents, who are first time mothers, face significant risks during pregnancy, including obstetric fistula and maternal death. Due to the fact that they start childbearing early; a married girl will likely have more children and at shorter intervals during her lifetime. The abovementioned factors; a young age, multiple children and a short interval between births, are all linked or related to a higher risk of death and disability due to pregnancy or childbirth.

The pregnant teenagers were significantly more likely to have experienced forced sexual initiation and were beaten more often. The findings further indicated that both forced sexual initiation and unwillingness to confront an unfaithful partner were strongly associated with the pregnancy.

Furthermore, the USAID (2011) report indicates that while 98\% of young people were informed about contraceptives, only $8.7 \%$ of them use it which is describes as ignorance from the side of the adolescent girls. This claim is also substantiated by UNICEF's report, which indicates that adolescent girls in Namibia have low level of contraceptive use and, only above $61 \%$ of condom use(2012).

Lillian \& Mumbango (2015) pointed out that, attitudes, multiple sexual partners as well as other factors were linked to risk factors for adolescent pregnancy. Chinsembu et al (2008) conquered with the fact that the term that adolescent sexuality is an important public health issue, as it affects risks to contract HIV and other sexually transmitted infections. Sexual prevalence for school-going male in 2004 was $44 \%$ while for females it was $24.8 \%$ in Namibia. In the study parental supervision was negatively associated with sexual intercourse.

According to Mmari and Blum in (2009) they concur that the most important pregnancy risk factors are education and schooling; knowledge and attitudes related to condom and contraception; perceived sexual behavior of friends; partner approval and support for using condoms and contraceptives.

The study by Liang, (2013). mentioned that the young adolescents, who are first time mothers, face significant risks during pregnancy, including obstetric fistula and maternal death. Due to the fact that they start childbearing early; a married girl will likely have more children and at shorter intervals during her lifetime. The abovementioned factors; a young age, multiple children and a short interval between births, are all linked or related to a higher risk of death and disability due to pregnancy or childbirth. Adolescent pregnancy exposes young girls to the risk of HIV and sexually transmitted infections. Girls in a marriage or union often have older, more sexually experienced husbands or partners, lack the power to negotiate safer sex and have little access to family planning information.

The study by the Department of Reproductive Health and Research of the World Health Organization (2011) elaborated that the main immediate consequences of an unwanted pregnancy are: induced abortion, lack of prenatal care, personal and family disruption, adoption and abandonment.

In the study by the National Statistical Office United Nations Children's Fund (2008), it was clearly pointed out that promoting safer sexual behavior is critical for reducing HIV prevalence. The promotion and the use of condoms during sexual intercourse, specifically with non-regular partners, are especially important for reducing the spread of HIV. In most countries, over half of new HIV infections occur amongst young people aged 15-24 years, indicating that influencing the behavior of this age group is key to reducing new infections.

Study by Thornberry et al (2015), suggested that involvement in delinquency, drug use, and sexual behavior at an early age affects the adolescent risk behaviors which will have short- and long-term consequences that disrupt the orderly flow of later development, including impacts on patterns of partner relationships. The abovementioned view was supported by Olumide, et al (2014) indicating that adolescent substance use is still a major issue among adolescents around the world, with numerous consequences underscoring the need for continued research and interventions.

\section{Conclusion}

The study found that factors such as, the circumstances of first sexual intercourse; the gift after first intercourse, having more than one sexual partner in past 12 months, alcohol used and partners older than 5 years, were associated with adolescent pregnancy in Kavango region, Namibia. 
Texila International Journal of Public Health

Volume 4, Issue 4, Dec 2016

\section{Figures and tables}

Table 1. Potential risk characteristics -Association between abortion and orphan

\begin{tabular}{|c|c|c|c|c|c|c|}
\hline & & & \multicolumn{2}{|c|}{ Orphan } & \multirow[t]{2}{*}{ Total } & \multirow[t]{2}{*}{ P-value } \\
\hline & & & Yes & No & & \\
\hline \multirow[t]{4}{*}{ Abortion } & \multirow[t]{2}{*}{ Yes } & Count & 8 & 5 & 13 & \multirow[t]{6}{*}{0.004} \\
\hline & & $\begin{array}{l}\text { \% of } \\
\text { Total }\end{array}$ & $1.6 \%$ & $1.0 \%$ & $2.6 \%$ & \\
\hline & \multirow[t]{2}{*}{ No } & Count & 127 & 360 & 487 & \\
\hline & & $\begin{array}{l}\text { \% of } \\
\text { Total }\end{array}$ & $25.4 \%$ & $72.0 \%$ & $97.4 \%$ & \\
\hline \multirow{2}{*}{\multicolumn{2}{|c|}{ Total }} & Count & 135 & 365 & 500 & \\
\hline & & $\begin{array}{l}\% \text { of } \\
\text { Total }\end{array}$ & $27.0 \%$ & $73.0 \%$ & $100.0 \%$ & \\
\hline
\end{tabular}

* P-value statistically significant at the level of significant 0.05

Table 2. Risk Estimate

\begin{tabular}{|l|l|l|l|}
\hline \multirow{2}{*}{} & \multirow{2}{*}{ Value } & \multicolumn{2}{|c|}{$\begin{array}{c}\text { 95\% Confidence } \\
\text { Interval }\end{array}$} \\
\cline { 3 - 4 } & & Lower & Upper \\
\hline $\begin{array}{l}\text { Odds Ratio for Abortion } \\
\text { (Yes / No) }\end{array}$ & 4.535 & 1.457 & 14.118 \\
\hline For cohort Orphan= Yes & 2.360 & 1.497 & 3.720 \\
\hline For cohort Orphan= No & .520 & .261 & 1.037 \\
\hline N of Valid Cases & 500 & & 21.494 \\
\hline $\begin{array}{l}\text { Odds Ratio for Abortion } \\
\text { (Yes / No) }\end{array}$ & 2.622 & .320 & 17.516 \\
\hline $\begin{array}{l}\text { For cohort Marijuana }= \\
\text { Yes }\end{array}$ & 2.497 & .356 & 1.115 \\
\hline $\begin{array}{l}\text { For cohort Marijuana }= \\
\text { No }\end{array}$ & .952 & .813 & 60.047 \\
\hline N of Valid Cases & 500 & 3.410 & 36.092 \\
\hline $\begin{array}{l}\text { Odds Ratio for Abortion } \\
\text { (Yes / No) }\end{array}$ & 14.310 & 1.058 \\
\hline For cohort Drug = Yes & 11.238 & 3.499 & \\
\hline For cohort Drug = No & .785 & .583 & \\
\hline N of Valid Cases & 500 & & \\
\hline
\end{tabular}


Table 3. Potential risk characteristics-Association between abortion, marijuana and partner 5years older

\begin{tabular}{|c|c|c|c|c|c|c|}
\hline & \multicolumn{2}{|c|}{ Marijuana } & \multirow{2}{*}{ Total } & \multirow{2}{*}{$\begin{array}{l}\text { P-value } \\
\text { P-value }\end{array}$} \\
\hline & & & Yes & No & & \\
\hline \multirow[t]{4}{*}{ Abortion } & \multirow[t]{2}{*}{ Yes } & Count & 0.107 & 12 & 13 & \multirow[t]{6}{*}{0.000} \\
\hline & & $\begin{array}{l}\text { \% of } \\
\text { Total }\end{array}$ & $0.2 \%$ & $2.4 \%$ & $2.6 \%$ & \\
\hline & \multirow[t]{2}{*}{ No } & Count & 15 & 472 & 487 & \\
\hline & & $\begin{array}{l}\text { \% of } \\
\text { Total }\end{array}$ & $3.0 \%$ & $94.4 \%$ & $97.4 \%$ & \\
\hline \multirow{2}{*}{\multicolumn{2}{|c|}{ Total }} & Count & 16 & 484 & 500 & \\
\hline & & $\begin{array}{l}\text { \% of } \\
\text { Total }\end{array}$ & $3.2 \%$ & $96.8 \%$ & $100.0 \%$ & \\
\hline \multirow[t]{4}{*}{ Abortion } & \multirow[t]{2}{*}{ Yes } & Count & 3 & 10 & 13 & \multirow[t]{6}{*}{0.000} \\
\hline & & $\begin{array}{l}\text { \% of } \\
\text { Total }\end{array}$ & $0.6 \%$ & $2.0 \%$ & $2.6 \%$ & \\
\hline & \multirow[t]{2}{*}{ No } & Count & 10 & 477 & 487 & \\
\hline & & $\begin{array}{l}\text { \% of } \\
\text { Total }\end{array}$ & $2.0 \%$ & $95.4 \%$ & $97.4 \%$ & \\
\hline \multirow{2}{*}{\multicolumn{2}{|c|}{ Total }} & Count & 13 & 487 & 500 & \\
\hline & & $\begin{array}{l}\text { \% of } \\
\text { Total }\end{array}$ & $2.6 \%$ & $97.4 \%$ & $100.0 \%$ & \\
\hline & & & \multicolumn{2}{|c|}{ Partner 5years older } & \multirow[t]{2}{*}{ Total } & \multirow[t]{2}{*}{ P-value } \\
\hline & & & Yes & No & & \\
\hline \multirow{2}{*}{$\begin{array}{l}\text { Currently } \\
\text { Pregnant }\end{array}$} & \multirow{2}{*}{\multicolumn{2}{|c|}{\begin{tabular}{|c|} 
Yes \\
No
\end{tabular}}} & 13 & 53 & 66 & \multirow[t]{3}{*}{0.107} \\
\hline & & & 54 & 380 & 434 & \\
\hline \multicolumn{3}{|l|}{ Total } & 67 & 433 & 500 & \\
\hline
\end{tabular}

* P-value statistically significant at the level of significant 0.05

Table 4. Potential risk characteristics -Association between gender of participants, had sex regularly, alcohol used, partner 5years older and sexual partner in past 12 months.

\begin{tabular}{|c|c|c|c|c|c|c|}
\hline & \multicolumn{2}{|c|}{$\begin{array}{l}\text { Gender } \\
\text { participants }\end{array}$} & \multirow[t]{2}{*}{ Total } & \multirow[t]{2}{*}{$\begin{array}{l}\mathrm{P}- \\
\text { value }\end{array}$} \\
\hline & & & Male & Female & & \\
\hline \multirow{10}{*}{$\begin{array}{l}\text { Sex } \\
\text { regularly }\end{array}$} & \multirow[t]{4}{*}{ Yes } & Count & 53 & 33 & 86 & \multirow[t]{10}{*}{0.001} \\
\hline & & \% within Sex regularly. & $61.6 \%$ & $38.4 \%$ & 100.0 & \\
\hline & & 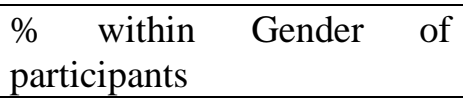 & $24.0 \%$ & $11.8 \%$ & $17.2 \%$ & \\
\hline & & $\%$ of Total & $10.6 \%$ & $6.6 \%$ & $17.2 \%$ & \\
\hline & \multirow[t]{4}{*}{ No } & Count & 107 & 175 & 282 & \\
\hline & & \% within Sex regularly. & $37.9 \%$ & $62.1 \%$ & $\begin{array}{l}100.0 \\
\%\end{array}$ & \\
\hline & & 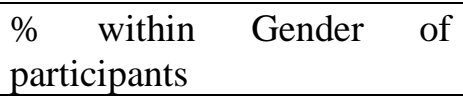 & $48.4 \%$ & $62.7 \%$ & $56.4 \%$ & \\
\hline & & $\%$ of Total & $21.4 \%$ & $35.0 \%$ & $56.4 \%$ & \\
\hline & \multirow[t]{2}{*}{ Not applicable } & Count & 56 & 70 & 126 & \\
\hline & & \% within Sex regularly. & $44.4 \%$ & $55.6 \%$ & $\begin{array}{l}100.0 \\
\%\end{array}$ & \\
\hline
\end{tabular}


Texila International Journal of Public Health

Volume 4, Issue 4, Dec 2016

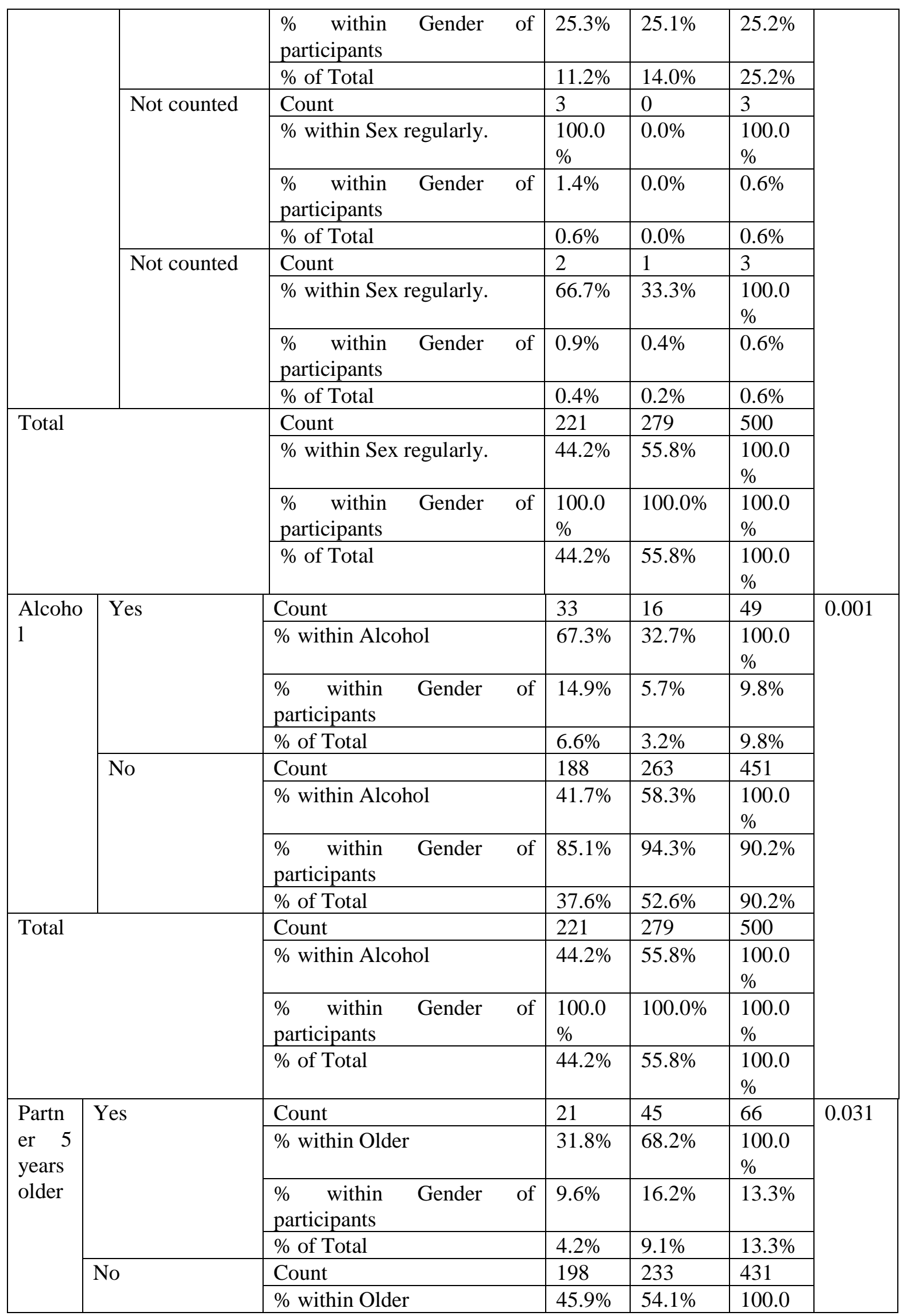




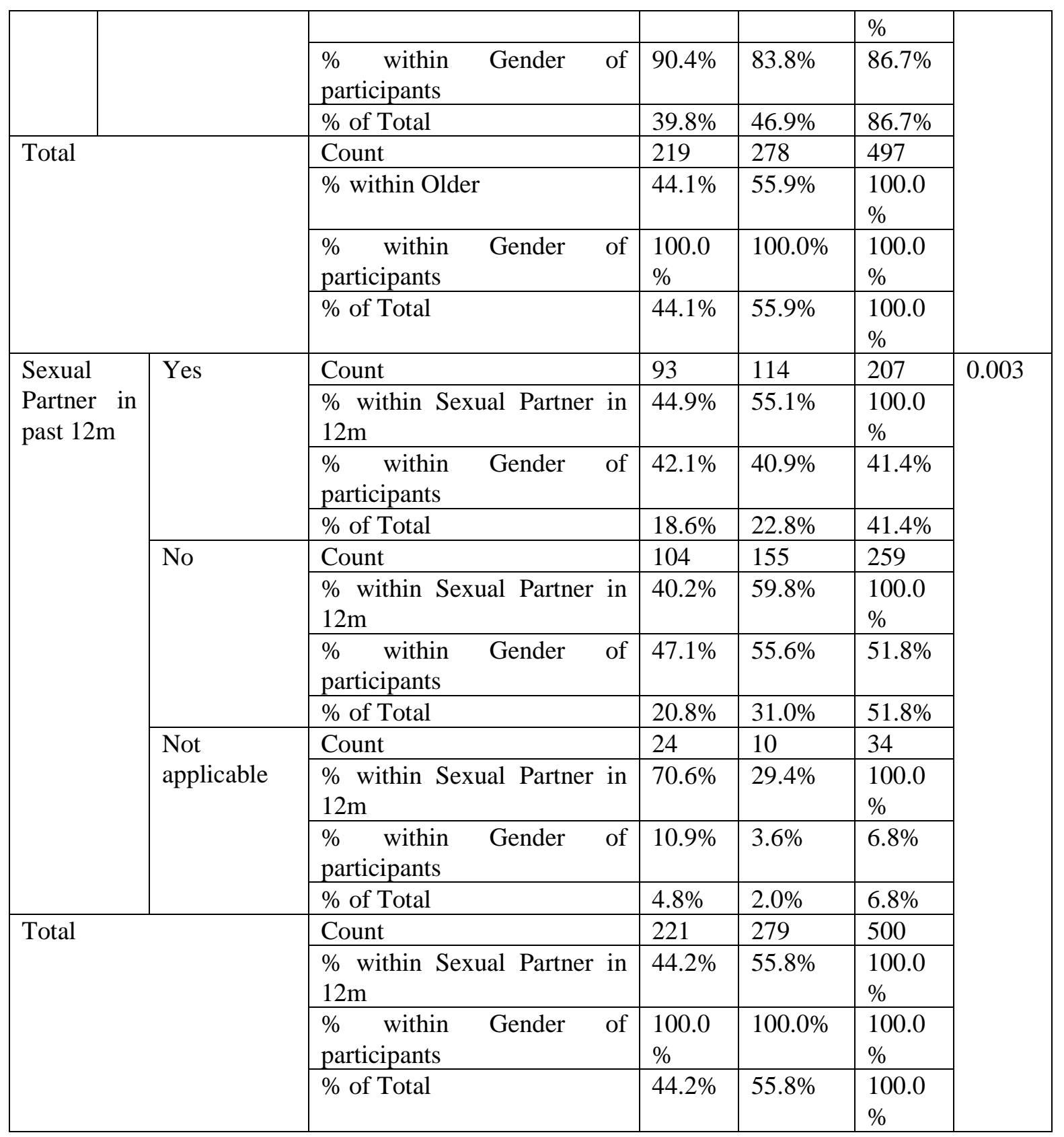

* P-value statistically significant at the level of significant 0.05

\section{References}

[1]. Chisembu K.C., Siziya.S. Muula. A.S. (2008). Prevalence and Social Correlates of Sexual Intercourse among School going Adolescents in Namibia.

[2]. Department of Reproductive Health and Research World Health Organization. (2011). Adolescent Pregnancy. Avenue Appia 20, CH-1211 Geneva 27, Switzerland E-mail: reproductivehealth@who.int.

[3]. Liang, E.L.M. (2013). Adolescent Pregnancy: A Review of the Evidence. UNFPA New York, 2013

[4]. Lillian P, Mumbango T (2015) Statistical Modeling of Adolescent Pregnancy in Namibia. J Nurs Care 4: 262. doi: Volume $4 \cdot$ Issue $4 \cdot 10.4172 / 2167-1168.1000262$.

[5]. Mufune. P. (2003). Changing Patterns of sexuality in Northern Namibia: Implication a for the transmission of HIV/AIDS.

[6]. Minesota Department of Health. (2010). Adolescent Pregnancy Prevention Interventions. Website:http://www.advocatesforyouth.org/storage/advfy/documents/sspregnancies.pdf. 
Texila International Journal of Public Health

Volume 4, Issue 4, Dec 2016

[7]. Mmari, K. \& Blum, R.W. (2009). Risk and Protective Factors that Affects Adolescents Reproductive health in Developing Countries: A structured Literature review. Global Public Health.

[8]. Nomhle Kangootui. Namibian Newspaper, 14 July 2016. Pregnancy statistics in Namibia. Windhoek.

[9]. National Statistical Office United Nations Children's Fund. (2008). Teenage Pregnancy and Motherhood. Malawi.

[10]. Olumide, A. O., Robinson, A. C., Levy, P. A., Mashimbye, L., Brahmbhatt, H., Lian, Q., Blum, R. W. (2014). Predictors of Substance use among Vulnerable Adolescents in five cities: findings from the well being of Adolescents in Vulnerable Environments Study. The Journal of Adolescent Health $\square$ : Official Publication of the Society for Adolescent Medicine, 55(6 Suppl), S39-47. http://doi.org/10.1016/j.jadohealth.2014.08.024.

[11]. Omar, K., Hasim, S., Muhammad, N. A., Jaffar, A., Hashim, S. M., \& Siraj, H. H. (2010). Adolescent Pregnancy Outcomes and Risk factors in Malaysia. http://doi.org/10.1016/j.ijgo.2010.06.023

[12]. Thornberry, T. P., Krohn, M. D., Augustyn, M. B., Buchanan, M., \& Greenman, S. J. (2015). The impact of Adolescent risk behavior on Partner Relationships. Advances in Life Course Research. http://doi.org/10.1016/j.alcr.2015.04.002

[13]. UNICEF. (2012). Progress for Children: A Report Card on Adolescents, No 10, April 2012.

[14]. UNFPA(2013). World Population Day the United Nations Population Fund.

[15]. USAID (2011). Teenage Pregnancy in Kavango Region. Contributing Factors and. Program Recommendations.

[16]. WHO (2014). Adolescent Pregnancy Fact Sheet, Department of Reproductive Health and Research, Geneva, Switzerland. 